MATEC Web of Conferences 26,01010 (2015)

DOI: $10.1051 /$ matecconf/ 20152601010

(C) Owned by the authors, published by EDP Sciences, 2015

\title{
Finite Element Modeling of Roll Wear during Cold Asymmetric Sheet Rolling of Aluminum Alloy 5083
}

\author{
Pesin A. ${ }^{1}$, Pustovoytov D. ${ }^{1}$, Shveyova T. ${ }^{1}$, Sverdlik M. ${ }^{1}$ \\ ${ }^{I}$ Nosov Magnitogorsk State Technical University, \\ 38, Lenin prospect, Magnitogorsk, 455000, Russia
}

\begin{abstract}
Since the main purpose of asymmetrical rolling is to impose high shear strains on the sheet, in order to obtain ultrafine grain structure, the friction between the rolls and the sheet has to be kept relatively high. This means that asymmetric rolling is performed with dry rolls. The paper presents a numerical analysis of the roll wear during asymmetric cold rolling of 5083 aluminum alloy. The finite element simulation was used to calculate the amount of roll wear by Usui's equation. FEM simulations were carried out with using software DEFORM 2D. The influence of the friction coefficient on the roll wear and the material flow was discussed. The sliding velocity, interface pressure and temperature were used to calculate the roll wear. The results of simulation can be used to optimize the asymmetric rolling process to improve surface quality of aluminum sheets.
\end{abstract}

\section{Introduction}

Creation of new materials with pre-defined properties is considered in the entire world as one of the key areas of the technological progress. Aluminum and its alloys are widely used as structural materials in aerospace, automotive and other industries due to low density and high specific strength [1]. Conventional approaches to increasing strength properties of aluminum alloys based on modification of their chemistry by alloying and on development of heat treatment and thermomechanical treatment methods are almost exhausted [2]. A more efficient way to further increase strength and other operational and technological properties of aluminum alloys is to form an ultra-fine grain structure using severe plastic deformation (SPD) methods. Many different SPD processes have been developed to date [3-4]. Severe plastic deformation can also be obtained by asymmetric rolling [5-6]. Since the asymmetric rolling is a continuous process, it has great potential for industrial production of ultrafine grain structure aluminum alloys. Asymmetry during rolling can be achieved due to different angular speeds or roll diameters. Asymmetric rolling with different angular speeds is more available for industrial application.

It is well known that the mechanism of SPD during cold rolling comes from its large equivalent strain, which is composed of compressive strain and additional shear strain. High friction coefficient increases the shear strain [7]. Shear strain is strongly depends on friction forces and it is too small during conventional cold rolling with lubrication. During asymmetric cold rolling opposite high friction forces creates very high shear strain. So asymmetric cold rolling should be carried out without lubrication. But a high friction coefficient is not desirable, not only because of the energy wasted but also because of the wear increasing of the sliding system.

In [8] an investigation of the wear mechanisms in the cold rolling of aluminum strip was reported. The effects of the pass reduction, the viscosity of the lubricant and the additives in the lubricant on wear were researched by measuring the relative mass wear rate and by observation of the rolled surface by means of optical microscopy and scanning electron microscopy. Chen and Thomson [9] studied the effect of applied load and temperature on the wear behavior of 5083 and 7075 alloy. They observed that the dominant wear mechanisms of 5083 and 7075 aluminum alloys were: adhesion, plastic deformation and abrasion. The above wear mechanisms were found to depend mainly on the applied load. Meyer-Rodenbeck et al. [10] studied the wear behavior of a wide range of cast and wrought aluminum alloys, under abrasive and corrosive wear conditions. These investigators found that wrought aluminum alloys $7017,7075,5083$ and 5251 provided the best wear resistance, under the selected conditions. These investigators related the microstructure with the wear resistance of the examined alloys. The effect of cold deformation on the lubricated wear of 5083 aluminum alloy was investigated in [11] research paper. The aluminum alloy was submitted to a cold rolling process, until the average thickness of the specimens was reduced by $7 \%$ and $15 \%$ respectively. In all cases, the three lubrication regimes were identified. The 
dominant wear mechanisms in each lubrication regime were studied.

To obtain a high uniform shear strain [12] and ultrafine grain structure through the sheet thickness during asymmetric rolling of aluminum alloys is necessary: 1) contact friction should be very high (friction coefficient is about 0.32); 2) thickness reduction per pass should be very high (about $50 \%$ or more); 3) mismatch factor of roll velocities should be equal to thickness reduction per pass and should be no less then 2. However it can be the reason of a high depth of roll wear. The works and projects known to the authors of this paper lack the data on influence of asymmetric rolling parameters (e.g., mismatch ratio of the roll velocities, reduction per pass, work roll radius, friction coefficient) on the roll wear. The goal of this research is to determine and to compare the roll wear during symmetric and asymmetric cold rolling of 5083 aluminum alloy.

\section{Research method}

Commercial software DEFORM 2D, based on finite element method (FEM), was used to analyze roll wear during symmetric and asymmetric cold rolling processes. The wear phenomenon in cold rolling is very complex. Many wear mechanisms exist described as adhesive wear, abrasive wear, diffusive wear, fatigue wear, etc. Adhesion for aluminum is always even more severe and occurs even when the rolls is very smooth. DEFORM 2D offers two kinds of tool wear model: Archard model and Usui model. Archard abrasive wear model is applicable to the non-continuous processes and can be viewed as a primary wear mechanism where the wear couple greatly differ in hardness. Usui model is applicable to the continuous process and can be viewed as a predominant wear mechanism with high friction, dry contact wear. Therefore, we choose Usui as the mathematical model of roll wear simulation analysis. Refer to Usui wear model (1) it is clear that interface pressure, absolute temperature of contact surface, sliding velocity are the main factors to affect the wear of work rolls.

$$
\mathrm{w}=\int \mathrm{apVe} \mathrm{e}^{-\mathrm{b} / \mathrm{T}} \mathrm{dt}
$$

where $\mathrm{w}$ - wear depth, $\mathrm{p}$ - interface pressure, V sliding velocity, $\mathrm{T}$ - interface absolute temperature, $a=3.85 e-09, b=1904-$ calibration coefficients.

In the course of simulation, the following assumptions were made: 1) plane strain of metal; 2) deformed medium - hardened rigid-plastic material; 3) work rolls - absolutely rigid; 4) conditions of deformation - nonisothermal. Initial temperature $20^{\circ} \mathrm{C}$. Heat transfer coefficient at the interface in all calculation variants was set constant and equal to 11
$\mathrm{N} / \mathrm{sec} / \mathrm{mm} /{ }^{\circ} \mathrm{C}$. A Coulomb friction model was used between rolls and sheet, which assumes that no relative motion occurs if the equivalent frictional stress is less than a critical value. The friction coefficient was calibrated by experimental tests and FEM simulations. Aluminum alloy 5083 from DEFORM 2D data base was chosen as a material for sheet. AISI D2 was chosen as a material for rolls. AISI D2 is a high-carbon chromium alloy steel. The initial data: 1) sheet thickness $2.0 \mathrm{~mm}$; 2) friction coefficient on the contact with the top and bottom rolls $\mu=0.08 \ldots 0.32$; 3) work roll radius $\mathrm{R}_{1}=\mathrm{R}_{2}=50 \mathrm{~mm}$; 4) mismatch factor of roll velocities $K_{v}=2$ (Eq. 2); 5) reduction per pass $\varepsilon=50 \%$. Peripheral speed of the bottom roll in all calculation variants was set constant, equal to $\mathrm{V}_{1}=1000 \mathrm{~mm} / \mathrm{sec}$; peripheral speed of the top roll was reduced by $\mathrm{K}_{\mathrm{v}}$ times.

$$
\mathrm{K}_{\mathrm{v}}=\mathrm{V}_{1} / \mathrm{V}_{2} \text {, where } \mathrm{V}_{1}>\mathrm{V}_{2}
$$

In the course of simulation of symmetric and asymmetric rolling the influence of the process parameters on roll wear was studied.

\section{Simulation results and discussion}

By analyzing the results of simulation for different rolling processes, it can be inferred that the roll wear is much smaller during symmetric rolling, when friction coefficient is less than 0.18 . However, if the friction coefficient is very high (for example, 0.32) then the roll wear is much smaller during asymmetric rolling (Fig. 1). It can be explained by different influence of interface temperature and pressure.

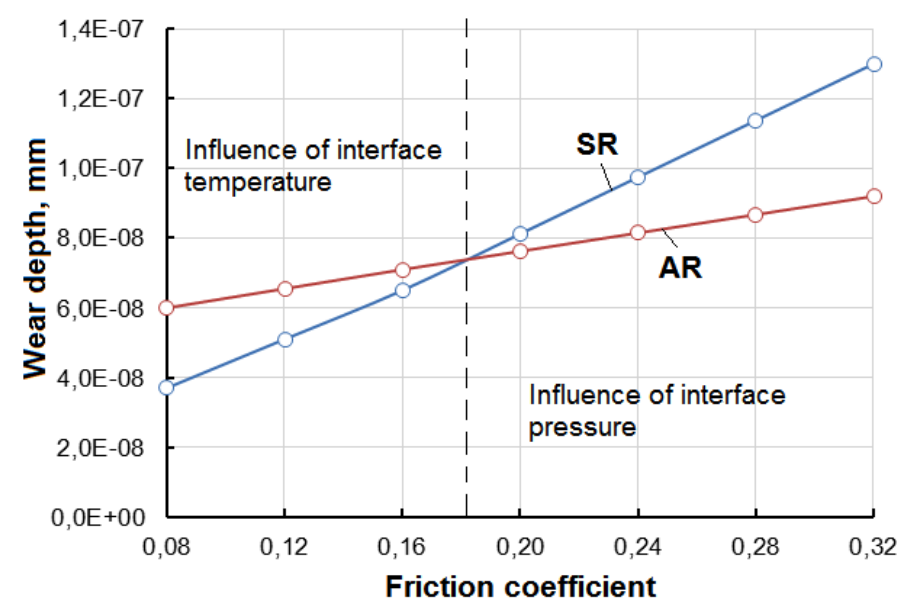

Figure 1. Interrelation of wear depth and friction coefficient during symmetric (SR) and asymmetric (AR) rolling with $\mathrm{Kv}=2$ (in all cases $\mathrm{h} 0=2 \mathrm{~mm}, \mathrm{e}=50 \%, \mathrm{R}=50 \mathrm{~mm}$ ) 


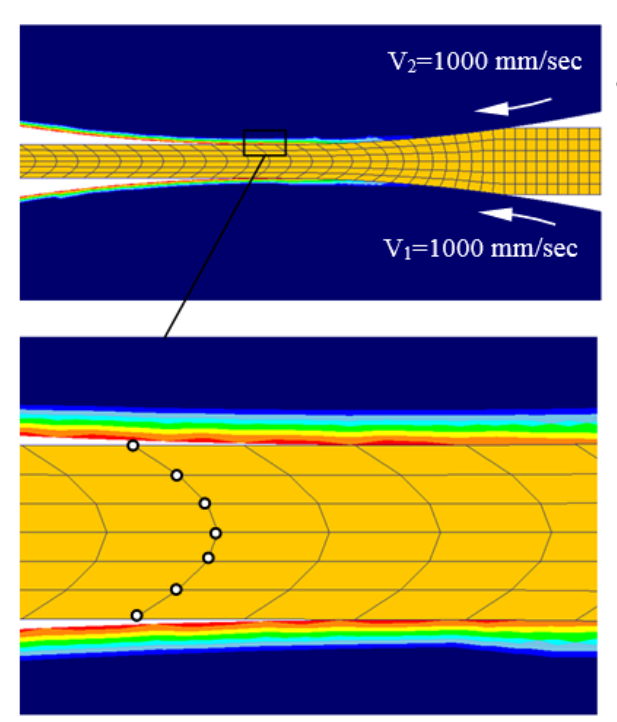

(a)

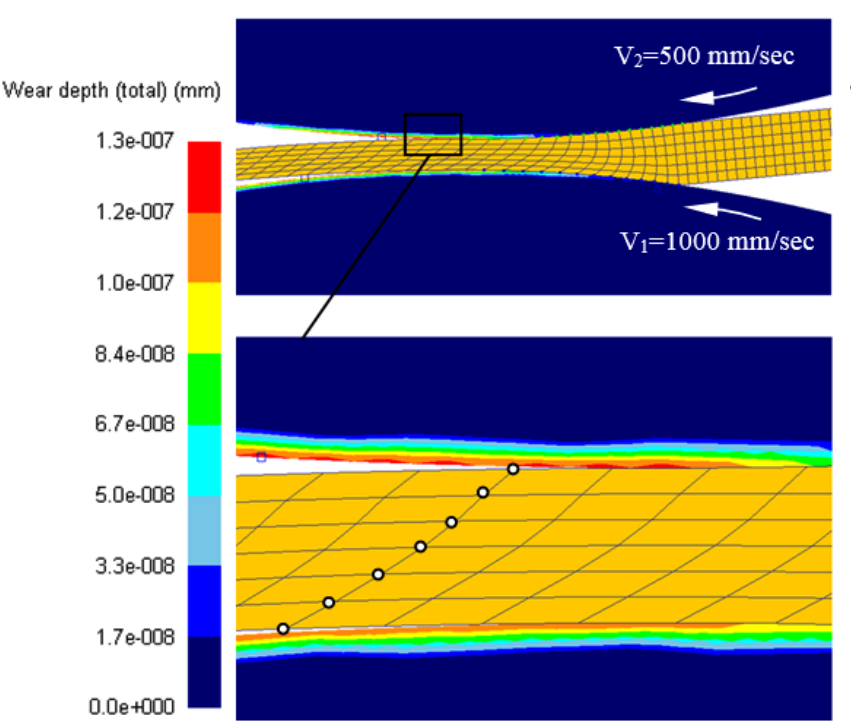

(b)
Wear depth (total) (mm)

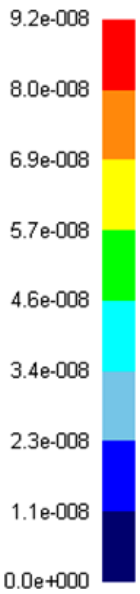

Figure 2. Roll wear during symmetric (a) and asymmetric (b) rolling with $\mathrm{Kv}=2$ (in both cases $\mathrm{h} 0=2 \mathrm{~mm}, \mathrm{e}=50 \%, \mathrm{R}=50 \mathrm{~mm}, \mathrm{~m}=0.32$ )

Interface pressure is one of the main factors that affect the amount of wear in Usui model. High friction coefficient increases the interface pressure. The larger is pressure on the contact surface, the more serious is wear. If friction coefficient is very low, then no significant effect on interface pressure during symmetric and asymmetric rolling. Deformation of the aluminum alloy 5083 during cold symmetric rolling provides very high interface pressure resulting from the high friction between the rolls and the sheet. The pressure at both interfaces is the same with the maximum pressure occurring at the neutral point (Fig. 3). However, increasing the friction coefficient results to serious reduction of interface pressure and roll wear during cold asymmetric rolling (Fig.3).

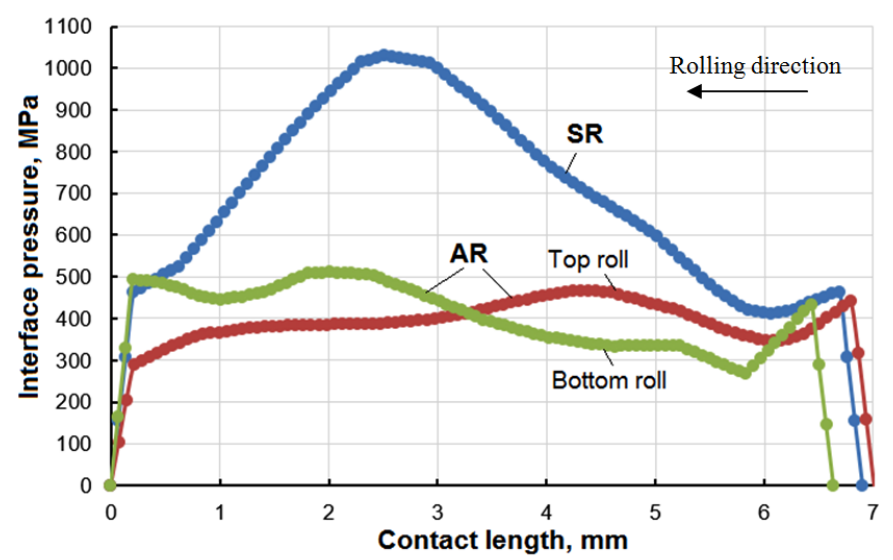

Figure 3. Interface pressure during symmetric (SR) and asymmetric rolling (AR) with $\mathrm{Kv}=2$ (in both cases $\mathrm{h} 0=2 \mathrm{~mm}$, $\mathrm{e}=50 \%, \mathrm{R}=50 \mathrm{~mm}, \mathrm{~m}=0.32$ )

According to the Usui wear model the temperature on the contact surface is another important factor that affects (b)

roll wear. The heat is produced by friction and plastic work. Higher is the temperature, more serious is roll wear, which is more obvious during high pass reduction. The interrelation of interface temperature and friction coefficient during symmetric and asymmetric rolling is shown in Fig. 4. The interface temperature is between 98 and $145{ }^{0} \mathrm{C}$ for SR and it is between 103 and $188{ }^{\circ} \mathrm{C}$ for AR. The temperature of 5083 aluminum sheet is highest during asymmetric rolling.

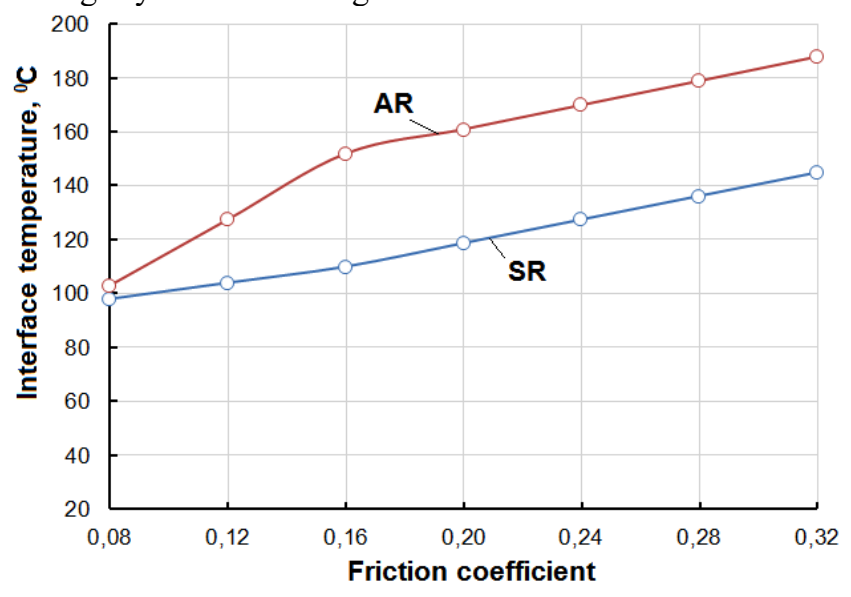

Figure 4. Interrelation of interface temperature and friction coefficient during symmetric (SR) and asymmetric (AR) rolling with $\mathrm{Kv}=2$ (in all cases $\mathrm{h} 0=2 \mathrm{~mm}, \mathrm{e}=50 \%, \mathrm{R}=50 \mathrm{~mm}$ )

\section{Conclusions}

The numerical determination of roll wear during cold asymmetric rolling was presented in this paper. The roll wear is much smaller during symmetric rolling, when friction coefficient is less than 0.18. However, if the friction coefficient is very high (for example, 0.32) then the roll wear is much smaller during asymmetric rolling. It can be explained by different influence of interface temperature and pressure. FE model can be used to predict the roll wear and to optimize the asymmetric rolling process to improve surface quality of aluminum sheets. Further experimental investigation of the roll wear during asymmetric sheet rolling is required. 


\section{Acknowledgements}

The study was supported by a grant of the Russian Science Foundation (project No15-19-10030)

\section{References}

1. V.V. Antipov, O.G. Senatorova, E.A. Tkachenko, R.O. Vakhromov, High-strength Al-Zn-Mg-Cu alloys and light Al-Li alloys, Metal Science and Heat Treatment. 9 (2011) 27-33.

2. V.I. Elagin, Paths of development of high-strength and heat-resistant structural aluminum alloys in the 21st century, Metal Science and Heat Treatment. 9 (2007) 3-11.

3. Laszlo S. Toth, Chengfan Gu, Ultrafine-grain metals by severe plastic deformation, Materials Characterization. 92 (2014) 1-14

4. R.K Islamgaliev, N.F Yunusova, I.N Sabirov, A.V Sergueeva, R.Z Valiev, Deformation behavior of nanostructured aluminum alloy processed by severe plastic deformation, Materials Science and Engineering: A. 319-321 (2001) 877-881.

5. Y.H. Ji, J.J. Park, Development of severe plastic deformation by various asymmetric rolling processes,
Materials Science and Engineering: A. 499 (2009) 14-17.

6. Jiang Jianhua, Ding Yi, Zuo Fangqing, Shan Aidang, Mechanical properties and microstructures of ultrafine-grained pure aluminum by asymmetric rolling, Scripta Materialia. 60 (2009) 905-908.

7. F. Zuo, J. Jiang, A. Shan, Shear deformation and grain refinement in pure Al by asymmetric rolling, Transactions of Nonferrous Metals Society of China. 18 (2008) 774-777.

8. Zhang Hui, Wang Manxing. A study of wear mechanisms in the cold rolling of aluminum strip, Journal of Materials Processing Technology. 31 (1992) 235-243.

9. Z. Chen, P.F. Thomson. Friction against superplastic aluminum alloys. Wear, 201 (1996) 227-232.

10. G. Meyer-Rodenbeck, T. Hurd, A. Ball. On the abrasive-corrosive wear of aluminum alloys, Wear. 154 (1992) 305-317.

11. C.N. Panagopoulos, E.P. Georgiou. Cold rolling and lubricated wear of 5083 aluminum alloy, Materials and Design. 31 (2010) 1050-1055

12. A. Pesin, D. Pustovoytov, Influence of process parameters on distribution of shear strain through sheet thickness in asymmet ric rolling, Key Engineering Materials. 622-623 (2014) 929-935. 